\title{
Impact of empirical oseltamivir discontinuation in hospitalized patients with community-acquired pneumonia after confirmed negative for influenza
}

\author{
Ashjan F. Alghanem, Pharm.D, Fahad A. Aldhahri, Pharm.D, Abdullah U. Althemery, PhD.
}

\begin{abstract}
الأهداف : الانفلونزا هو مرض محدد ذاتيًا لاغلب الافراد الصحيين ولكن احيانا

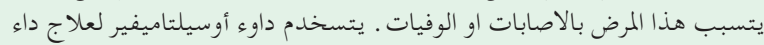



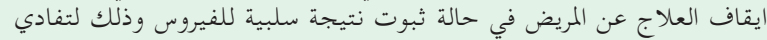

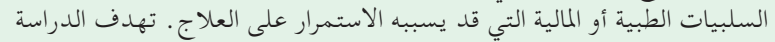

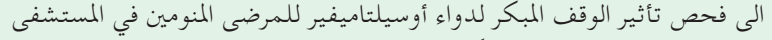

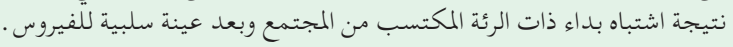

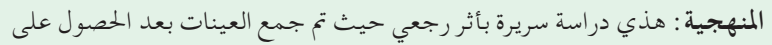

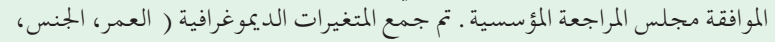

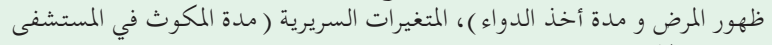

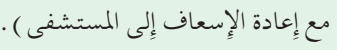

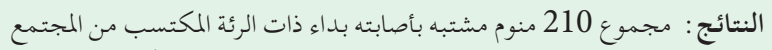

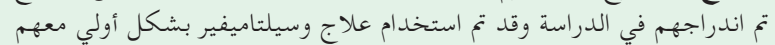

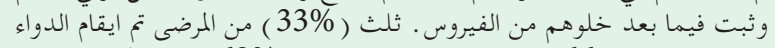

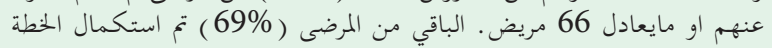

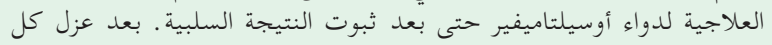

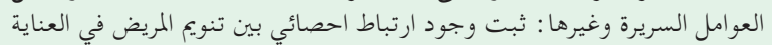
المركزة مع وقف الدواء المبكر مان.

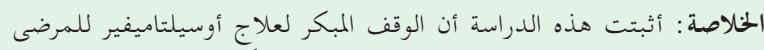

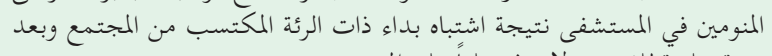



Objectives: To study the effect of appropriate oseltamivir discontinuation in patients hospitalized with pneumonia, after they tested negative for influenza.

Methods: A retrospective study was conducted at King Abdulaziz Medical City, Riyadh, Saudi Arabia. Patients admitted with a diagnosis of community-acquired pneumonia and started on empirical oseltamivir were included. The duration of stay at the hospital and readmission rates were identified. Additionally, we studied factors that led healthcare providers to continue patients on oseltamivir therapy despite testing negative for influenza.

Results: A total of 210 patients were studied. The rate of empirical oseltamivir appropriate discontinuation was $31 \%$ (66 patients). No significant difference was noted between the 2 groups in the length of hospital stay $(p=0.46)$. There was no significant difference in terms of 30-day (OR=0.67, 95\% CI [0.28-1.59]), 60-day $(\mathrm{OR}=1.14,95 \% \mathrm{CI}[0.47,2.78])$, and 90 -day readmission rates $(\mathrm{OR}=1.35,95 \% \mathrm{CI}[0.35-5.27])$. After adjusting for other variables, admission to the intensive care unit was independently associated with appropriate discontinuation compared with patients admitted to general wards.

Conclusions: This study showed that appropriate discontinuation of empirical antiviral therapy is safe, effective, and has no impact on the length of stay and readmission rates.

Keywords: oseltamivir, influenza, community-acquired pneumonia

Saudi Med J 2021; Vol. 42 (10): 1072-1077 doi: 10.15537/smj.2021.42.10.20210324

From the Pharmaceutical Care Services, Ministry of the National GuardHealth Affairs (Ashjan and Fahad), King Abdullah International Medical Research Center, and King Saud bin Abdulaziz University for Health Sciences, Riyadh; and from the Clinical Pharmacy Department, College of Pharmacy (Abdullah), Prince Sattam bin Abdulaziz University, Al-Kharj, Kingdom of Saudi Arabia.

Received 26th April 2021. Accepted 25th August 2021.

Address correspondence and reprint request to: Dr. Abdullah Althemery, Assistant Professor, Department of Clinical Pharmacy, College of Pharmacy, Prince Sattam Bin Abdulaziz University, Al-Kharj, Kingdom of Saudi Arabia.E-mail: A.althemery@psau.edu.sa

ORCID ID: http://orcid.org/0000-0002-3415-7685

$\mathrm{I}$ nfluenza is a respiratory viral infection that presents as a self-limiting disease in most individuals. ${ }^{1}$ Globally, the incidence of seasonal influenza is $7 \%-18 \%$, whereas the incidence of pandemic influenza is estimated to be higher, at approximately $20 \%-50 \% .^{2}$ According to the World Health Organization (WHO), 3-5 million 
people are severely ill each year due to influenza. ${ }^{3}$ Patients at risk of severe complications include the elderly, immunocompromised, and people with chronic conditions, such as pulmonary, cardiac, and metabolic diseases. $^{4-6}$

Oseltamivir is an antiviral agent belonging to the class of neuraminidase inhibitors and is used to treat and prevent influenza A and B viruses. ${ }^{7}$ Ample evidence exists regarding its effectiveness in treating hospitalized patients suspected of influenza. ${ }^{2,7-10}$ Jefferson et $\mathrm{al}^{7}$ found that oseltamivir significantly reduced symptom duration by an average of 16 hour. Moreover, Muthuri et $\mathrm{al}^{11}$ reported a significant reduction in mortality in patients treated with neuraminidase inhibitors during the 2009 influenza A (H1N1pdm09) pandemic. ${ }^{11}$ Because neuraminidase inhibitors, including oseltamivir, currently represent the most effective option available for treating influenza, ensuring their appropriate use is essential to maintaining their efficacy, as many studies have indicated that inappropriate medication can result in adverse drug reactions, and mortality particularly for elderly patients. ${ }^{12}$ More importantly, over-prescription of antimicrobials, including antivirals, can lead to resistance. ${ }^{13}$ In view of these considerations, antimicrobial stewardship programs are designed to ensure appropriate antimicrobial use in local healthcare institutions. ${ }^{14,15}$ One strategy for doing so involves narrowing an empirically broad antimicrobial regimen to specific coverage, depending on diagnostic information. ${ }^{16}$

Accordingly, the objectives of this study were to 1) determine the inappropriate use of the empirical antiviral oseltamivir, 2) explore factors likely to lead healthcare providers to continue patients on oseltamivir therapy despite testing negative for influenza, and 3) assess all-cause hospital length of stay and readmission after discharge for both appropriately and inappropriately treated groups.

Methods. A retrospective chart review was conducted at King Abdulaziz Medical City, Riyadh, Saudi Arabia, from January 2016 to December 2018. The study was approved by the Ethics Committee at King Abdullah International Medical Research Center. Data were collected using electronic medical records.

Disclosure. Authors have no conflict of interests, and the work was not supported or funded by any drug company.
Confidentiality was ensured by adherence to the World Medical Association Declaration of Helsinki ethical standards.

The study included adult patients ( $>18$ years) admitted to the hospital with a first-time diagnosis of community-acquired pneumonia (CAP) during the study period. All participants had a fever and one respiratory symptom (cough, sore throat, and nasal symptoms), with a multiplex polymerase chain reaction (PCR) panel test for respiratory viruses. Participants were treated empirically. Patients without a documented multiplex PCR panel report and those with confirmed positive influenza A or B infections were excluded.

The pneumonia diagnosis was confirmed by respiratory multiplex panel testing, a reverse transcriptase-PCR. The test was conducted using a nasopharyngeal swab. The testing panel targeted influenza $A$ and $B$ viruses, respiratory syncytial virus $A$ and $\mathrm{B}$, rhinovirus/enterovirus, parainfluenza virus $1-3$, adenovirus, human metapneumovirus, and coronavirus OC43 and 229E. The minimal analytical testing time was 4.5 hours, and turnaround times ranged from 6 to 24 hours. The duration of oseltamivir therapy was confirmed from the medication administration record and defined as the total number of days of oseltamivir therapy. The number of additional days a patient continued oseltamivir after a confirmed negative result was calculated separately based on the date of the influenza PCR test result and the date of the last dose of oseltamivir documented in the electronic medical record. The continuation of oseltamivir therapy was considered inappropriate if it was continued beyond 24 hours after the negative PCR multiplex result report date. We chose the 24 hours time frame because it is the acceptable time frame for health care teams to become aware of the result and take appropriate action. The 30-day, 60-day, and 90-day readmission rates were defined as any readmission due to pneumonia within 30,60 , and 90 days of patient discharge. Medical conditions were represented using the Charlson comorbidity index. ${ }^{17}$ The final score aggregated the following conditions: diabetes, hypertension, chronic kidney disease, liver disease, pulmonary disease, cardiovascular disease, and cancer. Antibiotic administration was classified as aminoglycosides, vancomycin, colistin, sulfonamides, penicillins, cephalosporins, and carbapenems.

This study aimed to identify factors that led clinicians to inappropriately continue oseltamivir therapy when the results of influenza PCR were negative. The outcome variable was defined as continuing oseltamivir treatment, which could be explained in part by 2 domains: modifying factors and perception variables. 
Modifying factors included age, gender, body mass index, and admission year. Perception variables included the type of patient (intensive care unit (ICU) patients or general ward patients), comorbidities, and antibiotic administration.

Statistical analysis. The sample size was determined using the $\mathrm{G}^{*}$ Power analysis software. The formula was calculated for $\mathrm{z}$ tests, particularly the logistic regression analysis family. The population proportion was acquired from previous literature, and the alpha error was specified at the 0.05 level. Based on these calculations, the minimum required sample size was 200. ${ }^{4,18}$ A purposive sampling technique was used to reach the minimum required number of patients, plus an additional $5 \%$ to allow for missing values in the medical records.

The dependent variable (empirical oseltamivir discontinuation) and the independent variables (age, gender, body mass index, admission year, patients in ICU, comorbidities, and antibiotic administration) were all classified into categorical variables. Independent frequency tests were explored using Chi-squared tests, with inferential statistics applied using stepwise logistic regression to test each factor while controlling for other factors. Finally, prediction models were estimated for different readmission rates and length of stay by continued use of empirical oseltamivir therapy, validated through bootstrapping techniques. ${ }^{19}$

Table 1 - Baseline characteristics.

\begin{tabular}{lccc}
\hline Factor & \multicolumn{3}{c}{ Empirical oseltamivir discontinuation } \\
& $\begin{array}{c}\text { Appropriate } \\
(\mathbf{n}=66)\end{array}$ & $\begin{array}{c}\text { Late } \\
(\mathbf{n}=144)\end{array}$ & $\begin{array}{c}\text { Total } \\
(\mathbf{n}=210)\end{array}$ \\
\hline $\begin{array}{l}\text { Percentage of diabetes } \\
\text { diagnosis }\end{array}$ & $45.45 \%$ & $46.53 \%$ & $46.19 \%$ \\
$\begin{array}{l}\text { Percentage of hypertension } \\
\text { diagnosis }\end{array}$ & $51.52 \%$ & $54.86 \%$ & $53.81 \%$ \\
$\begin{array}{l}\text { Percentage of chronic kidney } \\
\text { diseases }\end{array}$ & $19.70 \%$ & $7.64 \%$ & $11.43 \%$ \\
$\begin{array}{l}\text { Percentage of liver } \\
\text { disease diagnosis }\end{array}$ & $6.06 \%$ & $7.69 \%$ & $7.18 \%$ \\
$\begin{array}{l}\text { Percentage of pulmonary } \\
\text { disease diagnosis }\end{array}$ & $34.85 \%$ & $29.86 \%$ & $31.43 \%$ \\
$\begin{array}{l}\text { Percentage of cardiovascular } \\
\text { diagnosis }\end{array}$ & $45.45 \%$ & $34.72 \%$ & $38.10 \%$ \\
$\begin{array}{l}\text { Percentage of cancer diagnosis } \\
\begin{array}{l}\text { Average baseline creatinine } \\
\text { clearance }\end{array}\end{array}$ & $10.61 \%$ & $8.33 \%$ & $9.05 \%$ \\
\begin{tabular}{l} 
Average length of stay \\
\hline
\end{tabular} & 65.08 & 72.87 & 70.41 \\
\hline
\end{tabular}

Results. From January 2016 to December 2018, a sample of 210 patients diagnosed with CAP and started on empirical oseltamivir was included. Half of these patients $(51 \%)$ were female, and the mean age was 61 years $(\mathrm{SD}=20)$. A significant percentage of the patients were diagnosed with hypertension (53\%), diabetes (46\%), pulmonary diseases (31\%), and chronic kidney disease (11\%) (Table 1). Most patients (69\%) continued oseltamivir beyond 24 hours after testing negative for influenza and were classified as inappropriate (late discontinuation). The median duration of oseltamivir therapy was 3 days. Overall, most patients had mild to moderate disease. Only 20\% of the patients had severe disease and required ICU admission. When evaluating concurrent bacterial infections, almost all the patients had microbiologic culture specimens obtained during hospitalization (93\%). Only 33\% of the patients had concurrent confirmed positive bacterial infections (Table 2).

There was no significant difference between the late and appropriate discontinuation groups in terms of the frequencies of modifying variables (Table 3) and perception variables (Table 4), except that a significantly higher percentage of ICU patients were in the appropriate discontinuation group compared to non-ICU patients $(52.3 \%$ and $26.1 \%$ respectively, $p=0.02$ ). On evaluating the factors associated with the appropriate discontinuation of oseltamivir (Table 5) it was found that patients who were admitted to the ICU were more likely to discontinue oseltamivir after testing negative for influenza (OR, 0.3; 95\% CI, 0.14-0.64).

Table 2 - Associated infection during hospital stay.

\begin{tabular}{lccc}
\hline Factor & \multicolumn{2}{c}{ Empirical oseltamivir discontinuation } \\
& $\begin{array}{c}\text { Appropriate } \\
(\mathbf{n}=66)\end{array}$ & $\begin{array}{c}\text { Late } \\
(\mathbf{n}=\mathbf{1 4 4})\end{array}$ & $\begin{array}{c}\text { Total } \\
(\mathbf{n}=210)\end{array}$ \\
\hline $\begin{array}{l}\text { Percentage of concurrent viral } \\
\text { infection* }\end{array}$ & $1.52 \%$ & $6.25 \%$ & $4.76 \%$ \\
$\begin{array}{l}\text { Percentage of bacterial } \\
\text { infection }\end{array}$ & $36.36 \%$ & $29.86 \%$ & $31.90 \%$ \\
$\begin{array}{l}\text { Percentage of bacterial } \\
\text { specimens from blood }\end{array}$ & $13.64 \%$ & $5.56 \%$ & $8.10 \%$ \\
$\begin{array}{l}\text { Percentage of bacterial } \\
\text { specimens from sputum }\end{array}$ & $15.15 \%$ & $15.97 \%$ & $15.71 \%$ \\
$\begin{array}{l}\text { Percentage of bacterial } \\
\text { specimens from urine }\end{array}$ & $9.09 \%$ & $9.72 \%$ & $9.52 \%$ \\
$\begin{array}{l}\text { Percentage of bacterial } \\
\text { specimens from cerebral }\end{array}$ & $0.00 \%$ & $0.69 \%$ & $0.48 \%$ \\
\hline $\begin{array}{l}\text { *viruses include Coronavirus, Adenovirus, Human metapseumovirus, } \\
\text { Rhinovirus, and Parainfleunza }\end{array}$ & \\
\hline
\end{tabular}


Table 3 - Frequency of modifying factors.

\begin{tabular}{|c|c|c|c|c|}
\hline \multirow[t]{2}{*}{ Factor } & \multicolumn{3}{|c|}{ Empirical oseltamivir discontinuation } & \multirow[b]{2}{*}{$P$-value } \\
\hline & $\begin{array}{c}\text { Appropriate } \\
(n=66)\end{array}$ & $\begin{array}{c}\text { Late } \\
(\mathrm{n}=144)\end{array}$ & $\begin{array}{l}\text { Total } \\
(\mathbf{n}=210)\end{array}$ & \\
\hline \multicolumn{5}{|l|}{ Age } \\
\hline$>65$ & $34(32.1)$ & $72(67.9)$ & 106 & 0.96 \\
\hline$\geq 65$ & $32(30.8)$ & $72(69.2)$ & 104 & \\
\hline \multicolumn{5}{|l|}{ Gender } \\
\hline Male & $30(29.4)$ & $72(70.6)$ & 104 & 0.64 \\
\hline Female & $36(33.3)$ & $72(66.7)$ & 108 & \\
\hline \multicolumn{5}{|l|}{ Body mass index } \\
\hline Underweight & $3(42.9)$ & $4(57.1)$ & 7 & 0.17 \\
\hline Normal & $15(23.1)$ & $50(76.9)$ & 65 & \\
\hline $\begin{array}{l}\text { Overweight \& } \\
\text { obese }\end{array}$ & $48(34.7)$ & $90(65.2)$ & 138 & \\
\hline \multicolumn{5}{|l|}{ Admission year } \\
\hline $2016-2017$ & $38(31.4)$ & $83(68.6)$ & 121 & 0.99 \\
\hline 2018-2019 & $28(31.4)$ & $61(68.5)$ & 89 & \\
\hline
\end{tabular}

Table 4 - Frequency of perception variables.

\begin{tabular}{|c|c|c|c|c|}
\hline \multirow[t]{2}{*}{ Factor } & \multicolumn{3}{|c|}{ Empirical oseltamivir discontinuation } & \multirow[b]{2}{*}{$P$-value } \\
\hline & $\begin{array}{c}\text { Appropriate } \\
(\mathrm{n}=66)\end{array}$ & $\underset{(n=144)}{\text { Late }}$ & $\begin{array}{c}\text { Total } \\
(\mathbf{n}=210)\end{array}$ & \\
\hline \multicolumn{5}{|l|}{ ICU patients } \\
\hline Non-ICU & $44(26.1)$ & $124(73.8)$ & 168 & 0.02 \\
\hline ICU & $22(52.3)$ & $20(47.6)$ & 42 & \\
\hline \multicolumn{5}{|c|}{ Concurrent antibiotic use } \\
\hline No & $5(38.4)$ & $8(61.5)$ & 13 & 0.55 \\
\hline Yes & $16(30.9)$ & $163(69.0)$ & 197 & \\
\hline \multicolumn{5}{|c|}{ Charlson comorbidity index ${ }^{*}$} \\
\hline Average score & 2.88 & 2.5 & 2.61 & 0.23 \\
\hline
\end{tabular}

Other factors, such as age, gender, and year of admission were not significantly associated with appropriate discontinuation. The readmission rates were compared between the appropriate and late discontinuation groups (Table 6). There was no significant difference between the 2 groups in terms of 30 -day $(\mathrm{OR}=0.67,95 \% \mathrm{CI}$ [0.28-1.59]), 60-day (OR=1.14, 95\% CI [0.47-2.78]), and 90-day readmission rates $(\mathrm{OR}=1.35,95 \% \mathrm{CI}$ [0.35-5.27] ). Moreover, no significant difference was noted between the 2 groups in terms of the mean length of stay $(p=0.46)$.

Discussion. Our objective was to investigate the clinical outcomes associated with the timely discontinuation of oseltamivir, particularly when the influenza virus was not detected. We hypothesized that knowledge of negative influenza results would lead physicians to discontinue oseltamivir and positively impact patients' clinical outcomes. The study showed that the rate of timely empirical oseltamivir discontinuation among patients admitted with CAP after confirmed negative influenza was suboptimal (31\%). The practice of timely de-escalation of antimicrobial therapy, including antivirals, is a critical part of an antimicrobial stewardship program to decrease the emergence of resistance and reduce the overall cost. ${ }^{20}$ Pettit et $\mathrm{al}^{21}$ reported a savings of approximately $\$ 34.16$ per patient when the mean time to discontinue oseltamivir was reduced. This cost-saving is expected to be much higher during influenza seasons when the 
use of antiviral oseltamivir is anticipated to be higher. Moreover, our study reported no additional benefits in readmission rates and hospital stay duration for patients who continued oseltamivir despite testing negative for influenza. This finding is similar to that of Bohan et $\mathrm{al}^{, 22}$ who investigated the outcome of antibiotic de-escalation in patients with healthcare-associated pneumonia and found it to be a safe practice with no impact on the 30-day readmission rate. On the contrary, it was associated with a modest reduction in hospital length of stay. ${ }^{22}$ Other studies have reported a beneficial effect of de-escalation practice. Tabah et $\mathrm{al}^{23}$ reported an association between reduction in mortality rates and

Table 5 - Logistic regression model predicting empirical oseltamivir discontinuation.

\begin{tabular}{|c|c|c|}
\hline \multirow[t]{2}{*}{ Odds ratio estimates } & \multicolumn{2}{|c|}{ Demographics and perception } \\
\hline & Odds ratio & $95 \% \mathrm{CI}$ \\
\hline \multicolumn{3}{|l|}{ Age } \\
\hline$>65$ & \multirow{2}{*}{1.145} & \multirow{2}{*}{$0.59-2.22$} \\
\hline$\geq 65$ & & \\
\hline \multicolumn{3}{|l|}{ Gender } \\
\hline Male & \multirow[b]{2}{*}{0.81} & \multirow[b]{2}{*}{$0.43-1.53$} \\
\hline Female & & \\
\hline \multicolumn{3}{|l|}{ Body mass index } \\
\hline Underweight & 2.23 & $0.40-13.1$ \\
\hline Overweight and obese & \multirow{2}{*}{1.89} & \multirow{2}{*}{$0.90-3.97$} \\
\hline Normal & & \\
\hline \multicolumn{3}{|l|}{ Admission year } \\
\hline 2016-2017 & \multirow{2}{*}{0.88} & \multirow{2}{*}{$0.46-1.68$} \\
\hline 2018-2019 & & \\
\hline \multicolumn{3}{|l|}{ ICU patients* } \\
\hline Yes & \multirow{2}{*}{0.30} & \multirow{2}{*}{$0.14-0.64$} \\
\hline No & & \\
\hline \multicolumn{3}{|l|}{ Antibiotic use } \\
\hline No & \multirow{2}{*}{1.29} & \multirow{2}{*}{$0.34-4.94$} \\
\hline Yes & & \\
\hline Charlson comorbidity & 1.16 & $0.96-1.42$ \\
\hline *Significant a & ICU: intens & \\
\hline
\end{tabular}

de-escalation of antibiotics, particularly in critically ill patients diagnosed with pneumonia. Notably, Bohan et $\mathrm{al}^{22}$ and Tabah et $\mathrm{al}^{23}$ studied antimicrobial agents in general, whereas our study explored patients empirically treated with oseltamivir.

One of our study observations that warrants further discussion is that ICU patients were more likely to have empirical oseltamivir discontinued after testing negative for influenza, which might be explained by the high level of care provided in this kind of setting. When testing the overall theoretical framework, perception factors had a greater impact on explaining the oseltamivir discontinuation predictive model, which could indicate that clinicians tend to follow guidelines more rigorously when treating patients with worse conditions. This result demonstrates that acute condition management is prone to similar trends highlighted with chronic conditions, where healthcare professionals adhere to guidelines predominantly with patients in worse conditions. ${ }^{24}$ One explanation for the late discontinuation could be the clinical suspicion of influenza, especially during peak influenza activity in the community, as influenza PCR testing is nearly $50 \%$ $70 \%$ sensitive for detecting influenza and approximately greater than $90 \%$ specific. ${ }^{25,26}$ However, as observed in our study, extending the antiviral duration after negative results did not result in any further benefit.

Study limitations. Our findings have important implications for antimicrobial stewardship programs. Appropriate oseltamivir discontinuation did not negatively affect patients' clinical outcomes. In contrast, it might carry possible benefits, such as decreasing the emergence of resistance, cost reduction, and appropriate utilization of health care resources. This study's limitations include its retrospective design and its reliance on documented medical records for data collection, including the diagnosis of pneumonia and the length of stay at the ICU, which might have affected our results. Moreover, the oseltamivir discontinuation rate was measured at a single institution, and the results might not apply to other institutions. However, the study adds to the limited literature, shedding light on

Table 6 - Predicting readmission rate and length of stay by continued empirical oseltamivir treatment.

\begin{tabular}{lcccc}
\hline Predictor & $\begin{array}{c}\text { 30-day readmission } \\
\text { Estimate } \\
(95 \% \mathrm{CI})\end{array}$ & $\begin{array}{c}\text { 60-day readmission } \\
(\mathbf{9 5 \%} \mathrm{CI})\end{array}$ & $\begin{array}{c}\text { 90-day readmission } \\
(\mathbf{9 5 \%} \mathrm{CI})\end{array}$ & $\begin{array}{c}\text { Length of stay } \\
\text { Estimate* } \\
(\boldsymbol{p} \text {-value })\end{array}$ \\
\hline $\begin{array}{l}\text { Empirical oseltamivir } \\
\text { discontinuation }\end{array}$ & $0.67(0.28-1.59)$ & $1.14(0.47-2.78)$ & $1.35(0.35-5.27)$ & $0.75(0.46)$ \\
\hline & *presented as mean \\
\hline
\end{tabular}


an issue that could minimize excess hospitalizations and prevent antimicrobial resistance.

In conclusion, timely discontinuation of antimicrobial therapy, including antiviral therapy, is an essential part of the antimicrobial stewardship program. This study showed that appropriate discontinuation of empirical antiviral therapy in patients with CAP is a safe and effective practice that does not negatively influence the hospital stay duration and readmission rate. Additional efforts may focus on unnecessary antimicrobial therapy optimization strategies. Future studies can focus on other potential benefits, such as cost savings and risk of resistance.

Acknowledgment. We would like to thank King Abdullah International Medical Research Center and Prince Sattam Bin Abdulaziz University, Al-Kharj, Saudi Arabia for their administrative support of this project.

\section{References}

1. Ghebrehewet S, MacPherson P, Ho A. Influenza. BMJ 2016; 355: i6258.

2. Moscona A. Neuraminidase inhibitors for influenza. N Engl J Med 2005; 353: 1363-1373.

3. World Health Organization. [cited 2020 June 5]. Available from: https://www.who.int/news-room/fact-sheets/detail/ influenza-(seasonal).

4. Molinari NAM, Ortega-Sanchez IR, Messonnier ML, Thompson WW, Wortley PM, Weintraub E, et al. The annual impact of seasonal influenza in the US: Measuring disease burden and costs. Vaccine 2007; 25: 5086-5096.

5. Thompson WW, Shay DK, Weintraub E, Brammer L, Bridges $\mathrm{CB}$, Cox NJ, et al. Influenza-associated hospitalizations in the United States. JAMA 2004; 292: 1333-1340.

6. Centers for Disease Control and Prevention (CDC. Estimates of deaths associated with seasonal influenza-United States, 1976-2007. MMWR 2010; 59: 1057-1062.

7. Jefferson T, Jones MA, Doshi P, Del Mar CB, Hama R, Thompson MJ, et al. Neuraminidase inhibitors for preventing and treating influenza in healthy adults and children. Cochrane Database of Systematic Reviews 2014; 2014: CD008965.

8. Dobson J, Whitley RJ, Pocock S, Monto AS. Oseltamivir treatment for influenza in adults: A meta-analysis of randomized controlled trials. Lancet 2015; 385: 1729-1737.

9. Treanor JJ, Hayden FG, Vrooman PS, Barbarash R, Bettis R, Riff D, et al. Efficacy and safety of the oral neuraminidase inhibitor oseltamivir in treating acute influenza: A randomized controlled trial. US Oral Neuraminidase Study Group. JAMA 2000; 283: 1016-1024.

10. Jefferson T, Jones M, Doshi P, Del Mar C. Neuraminidase inhibitors for preventing and treating influenza in healthy adults: Systematic review and meta-analysis. BMJ 2009; 339: b5106.

11. Muthuri SG, Venkatesan S, Myles PR, Leonardi-Bee J, Al Khuwaitir TSA, Al Mamun A, et al. Effectiveness of neuraminidase inhibitors in reducing mortality in patients admitted to hospital with influenza A H1N1pdm09 virus infection: A meta-analysis of individual participant data. Lancet 2014; 2: 395-404.
12. Klarin I, Wimo A, Fastbom J. The association of inappropriate drug use with hospitalisation and mortality: A population-based study of the very old. Drugs Aging 2005; 22: 69-82.

13. Hussain M, Galvin HD, Haw TY, Nutsford AN, Husain M. Drug resistance in influenza A virus: the epidemiology and management. Infect Drug Resist 2017; 10: 121.

14. Fishman N. Antimicrobial stewardship. Am J Infect Control 2006; 34 Supplement 1: S55-S63.

15. Centers for Disease Control and Prevention. Influenza antiviral medications: summary for clinicians. Atlanta: USA; 2014. p. 1729-1737.

16. Masterton RG. Antibiotic de-escalation. Crit Care Clin 2011; 27: 149-162.

17. D'Hoore W, Bouckaert A, Tilquin C. Practical considerations on the use of the Charlson comorbidity index with administrative data bases. J Clin Epidemiol 1996; 49: 1429-1433.

18. Faul F, Erdfelder E, Lang AG, Buchner A. G*Power 3: A flexible statistical power analysis program for the social, behavioral, and biomedical sciences. Behav Res Methods 2007; 39: 175-191.

19. Kulesa A, Krzywinski M, Blainey P, Altman N. Sampling distributions and the bootstrap. Nat Methods 2015; 12: 477-478.

20. Barlam TF, Cosgrove SE, Abbo LM, Macdougall C, Schuetz AN, Septimus EJ, et al. Implementing an antibiotic stewardship program: Guidelines by the Infectious Diseases Society of America and the Society for Healthcare Epidemiology of America. Clin Infect Dis 2016; 62: e51-e77.

21. Pettit NN, Matushek S, Charnot-Katsikas A, Tesic V, Boonlayangoor S, Brielmaier B, et al. Comparison of turnaround time and time to oseltamivir discontinuation between two respiratory viral panel testing methodologies. J Med Microbiol 2015; 64: 312-313.

22. Bohan JG, Remington R, Jones M, Samore M, Madaras-Kelly K. Outcomes associated with antimicrobial de-escalation of treatment for pneumonia within the veterans healthcare administration. Open Forum Infect Dis 2017; 4: ofw244.

23. Tabah A, Cotta MO, Garnacho-Montero J, Schouten J, Roberts JA, Lipman J, et al. A systematic review of the definitions, determinants, and clinical outcomes of antimicrobial Deescalation in the Intensive Care Unit. Clin Infect Dis 2016; 62: 1009-1017.

24. Jones JA, Reeve CA. Factors influencing the use of clinical guidelines by general practitioners working in a setting of complex multimorbidity: A case study by interviews. $B M C$ Fam Pract 2018; 19: 157.

25. Uyeki TM. Influenza diagnosis and treatment in children: A review of studies on clinically useful tests and antiviral treatment for influenza. Pediatr Infect Dis J 2003; 22: 164-177.

26. Uyeki TM, Bernstein HH, Bradley JS, Englund JA, File TM, Jr, Fry AM, et al. Clinical practice guidelines by the Infectious Diseases Society of America: 2018 update on diagnosis, treatment, chemoprophylaxis, and institutional outbreak management of seasonal influenza. Clin Infect Dis 2019; 68: e1-e47. 